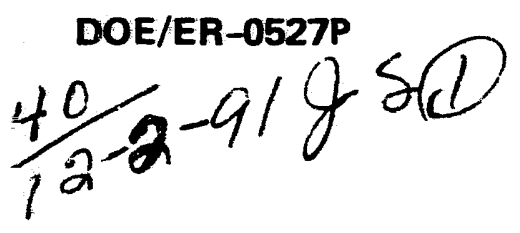

\title{
Summary Results of an Assessment of Research Projects in the
}

\section{Federal Wind Energy Research Program}

\section{October 1991}

U.S. Department of Energy Office of Energy Research Office of Program Analysis 
This report has been reproduced directly from the best available copy.

Available to DOE and DOE contractors from the Office of Scientific and Technical Information. P.O. Box 62, Oak Ridge, TN 37831; prices available from (615) 576-8401, FTS 626-8401.

A vailable to the public from the National Technical Information Service, U.S. Department of Commerce, 5285 Port Royal Rd., Springfield, VA 22161. 


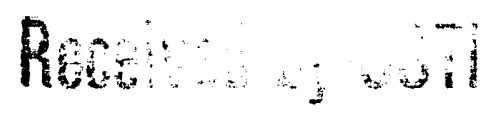

NOV 27.1991

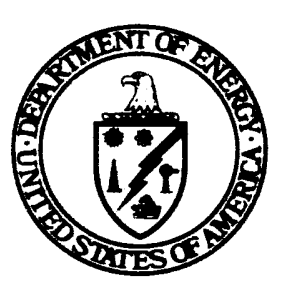

\section{Summary Results of an Assessment of Research Projects in the}

\section{Federal Wind Energy Research Program}

\section{October 1991}

U.S. Department of Energy Office of Energy Research Office of Program Analysis Washington, DC 20585

\section{MASTER}




\section{Introduction}

The Office of Program Analysis (OPA) undertook an assessment of 55 research projects sponsored by the Federal Wind Energy Research Program. This report summarizes the results of that review.

The Wind/Hydro/Ocean Division is responsible for the management of the Federal Wind Energy Research Program. In accordance with statute and policy guidance, the Federal Wind Energy Research Program's research has targeted the sciences of wind turbine dynamics and the development of advanced components and systems. Wind turbine research has focused on atmospheric fluid dynamics, aerodynamics, and structural dynamics.

The purpose of the assessment was to determine the following:

1. the quality of research of individual projects,

2. the impact of these inaividual projects on the mission of the program, and

3. priority future research targets and opportunities.

The assessment was conducted using the quantitative methodology developed by OPA for assessing the quality of research and development programs within DOE. This methodology is described in Procedures for Peer Review Assessments, DOE/ER-0491P. At the time of this review, it had been used by OPA in 16 prior assessments of over 1,500 projects in various DOE research programs.
The 55 research projects were reviewed by 7 panels of experts in review sessions held in Denver, Colorado, on April 30 to May 2, and in Albuquerque, New Mexico, on June 4 to 6, 1991. The six to nine reviewers comprising each panel were expert in the technical area, e.g., aerodynamics, addressed by the seven to eleven projects assigned to that panel. The reviewers participating in this assessment are listed in the appendix.

Rating factors included project scientific and technical merit, appropriateness and level of innovation of the technical approach, quality of the project team, productivity, and probable impact on the program's mission. Each project was also given an overall evaluation supported with written comments.

\section{Quality of the Projects Reviewed}

A project's overall evaluation was rated on a scale from 0.0 to 10.0 , with numerical values corresponding to a qualitative descriptor (e.g., outstanding, strong, good, needing management attention, or having serious shortcomings). Project overall evaluation ratings of 5.0 to 10.0 signify project quality ranging from good to outstanding. Conversely, descriptors below 5.0 identify projects with deficiencies or serious shortcomings that particularly warrant further review and attention from program management.

The figure on the following page summarizes the project overall evaluation ratings established for 52 of the 55 projects reviewed by the 7

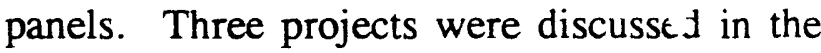
appropriate panels and comments provided, but 


\section{Cumulative Overall Project Evaluations Federal Wind Energy Research Program}

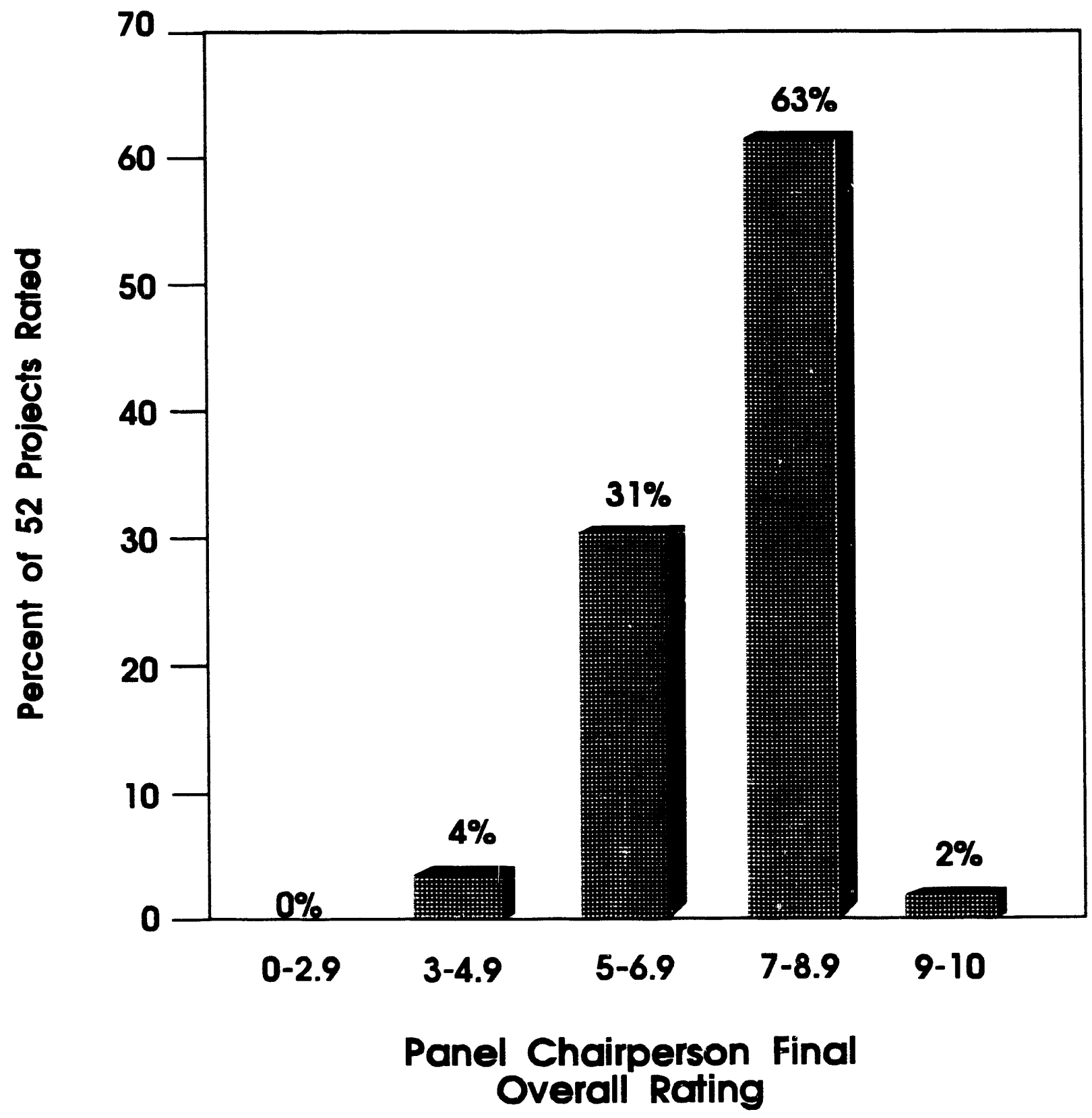

NOTE: An outstanding project would rate 9-10. A strong project deserving of continuing priority support would score 7-8.9, while a good project with negligible important shortcomings would receive a score o: 5-6.9. A project with some deficiencies or concerns that should be addressed would warrant a rating of 3-4.9 and a project with serious shortcomings that warrants close reevaluation would rank 0 2.9. 
the projects were not rated because it was either terminated before completion, placed on extended hold, or its objective was not sufficiently defined.

A total of 50 projects ( 96 percent of those rated) were judged to be good or better (i.e., had project overall evaluations of 5.0 or higher). Of these projects, 33 projects (63 percent of those rated) were judged to be strong (i.e., rated 7.0 to 8.9), and 1 project was judged to be outstanding (i.e., rated 9.0 to 10.0 ).

Conversely, two projects (4 percent) received project overall evaluation ratings lower than 5.0. The reviewers judged these to be projects with some deficiencies, or serious shortcomings, that need to be addressed by the program management.

\section{Targets for Future Research}

After completing project evaluations, the memhers of each pañei identified and discussed the topics they believed were the most important for future research in the technical areas of the projects assigned their panel. The panel chairperson, assisted by the other panel members, then determined those research topics believed to be of priority and provided written summaries of each.

\section{Turbulence Research}

Turbulence research was deemed to be one of the highest priorities. The clear need for understanding the nature of turbulence -- pdrticularly in its effects on wind turbine structures and components -- was held to be extremely important.

\section{Fundamental Aerodynamics Research}

A continuing research emphasis on the fundamentals of wind turbine aerodynamics was highly endorsed. Data and analytical results must be acquired to understand the basic physical mechanisms that determine blade airloads and airflow in the wide range of wind turbine environmental and design dependent conditions. The complex aerodynamic areas of unsteady stall and turbulence have been found to be significant for wind turbines. By understanding the fundamentals in these and other aerodynamic areas, the influence factors and design parameters for the airloads of wind turbines will be discovered. Fundamental understanding is also necessary for aerodynamic modeling in computer codes.

\section{Full Scale System Testing}

The development of structural models of wind turbines has advanced to the point where a broad-based program of full-scale system tests is vital for validation of the assumptions and methodologies. This topic includes full-scale testing of wind turbine systems of different sizes under a variety of operating conditions. It also includes modal testing of the rotating structure and development of design and scaling parameters.

\section{Modern Data Collection and Analysis Methods}

A cornprehensive research effort is urgently needed to apply modern data collection and analysis techniques to wind turbine performance monitoring. Examples of these state-of-the-art 
techniques include laser model analysis, ultrasonic methods, infrared sensing acoustic signatures, preprocessing of data, advanced data transmission methods such as microwave and satellite, statistical analysis methods, probabilistic risk analysis, and pattern recognition. Comprehensive field data on structural loads, dynamic response, and acoustical impact of wind energy conversion systems is lacking. One recent attempt to get such data was by Northern Power Systems under DOE sponsorship where 500 hours of field data were collected from a North Wind - $100(100 \mathrm{KW})$ machine. Although some 80 channels of data were collected on a magnetic tape, the process was very cumbersome. The techniques to store, quickly retrieve, manipulate, and analyze these data are apparently not in place, and use has been sporadic.

\section{Wind Turbine Array Effects Research}

Siting a windpark involves various tradeoffs between crosswind and downwind wind turbine spacing. A need exists to understand the tradeoffs and how to accommodate these effects in simple and complex terrain. Various gove $n$ ment and industry groups have attempted to address these issues, but there are severe limitations in the usefulness of previous work. For example, the bulk of previous wind turbine wake studies deals with single turbine measurements which are not applicable to large turbine arrays.

Further research should address the issue of wind turbine array effects within a windpark. Literature reviews, investigation of prior unpublished research, field measurement programs, and properly designed wind tunnel studies are recommended techniques and tools to accomplish this research.

\section{Materials and Components Research}

Further materials and components research is needed in the following areas to reduce costs and improve reliabilty and energy capture:

- mechanical, aerodynamic, and dynamic braking systems;

- blade materials and designs;

- control system strategy including starting, free wheeling, stopping, and variable speed for improver energy capture; and

- gear box and yaw system component design for improved reliability. 


\section{Reviewers}

Bilal M. Ayyub

University of Maryland

Bruce H. Bailey

AWS Scientific, Inc.

Robert Baker

Aerovironment

Jewel B. Barlow

University of Maryland

Nicholas G. Butler

Bonneville Power Administration

Jamie C. Chapman

Consultant

Allan B. Chertok

Certek Corporation

Richard Coulter

Argonne National Laboratory

David M. Eggleston

University of Texas of

the Permian Basin

Richard Everett

NASA Langley Research Center

Johnston J. Ford

Consultant

Peter Frayling

Lister-Petter, Inc.

Gary R. Halford

NASA Lewis Research Center
Dewey Hodges

Georgia Institute of Technology

Stephen Jones

Southwest Public Services Company

Stephen A. Justham

University of Kutztown

Jack Kline

Consultant

Thomas J. Kozik

Texas A\&M University

John A. Langrebe

United Technologies Research

Center

J. T. Lee

Los Alamos National Laboratory

Edward McCarthy

U.S. Wind Power

Barnes W. McCormick, Jr.

Pennsylvania State University

Rod D. Nierenberg

Consulting Meteorologist

Walter F. O'Brien

Virginia Polytechnic Institute and

State University

Dharam Pal

Naval Civil Engineering Laboratory 
Su-Seng Pang

Louisiana State Uriversity

David Popelka

Bell Helicopter Textron I

Patrick J. A. Quinlan

NEOS Corporation

Real Reid

Hydro-Quebec Research Institute

Michael C. Robinson

University of Colorado

Lawrence A. Schienbein

Flowing Corporation

George J. Schneider

Sikorsky Aircraft

Joseph S. Shangl

Wright-Patterson AFB
David Spera

Consultant

William J. Steely

Pacific Gas \& Electric Company

Homer J. Stewart

Consultant

Dan Suehiro

Hawaiian Electric Renewable Systems

Andrew H. P. Swift, Jr.

University of Texas at El Paso

Dan Vicroy

NASA Langley Research Center

William H. Wentz

Wichita State University 

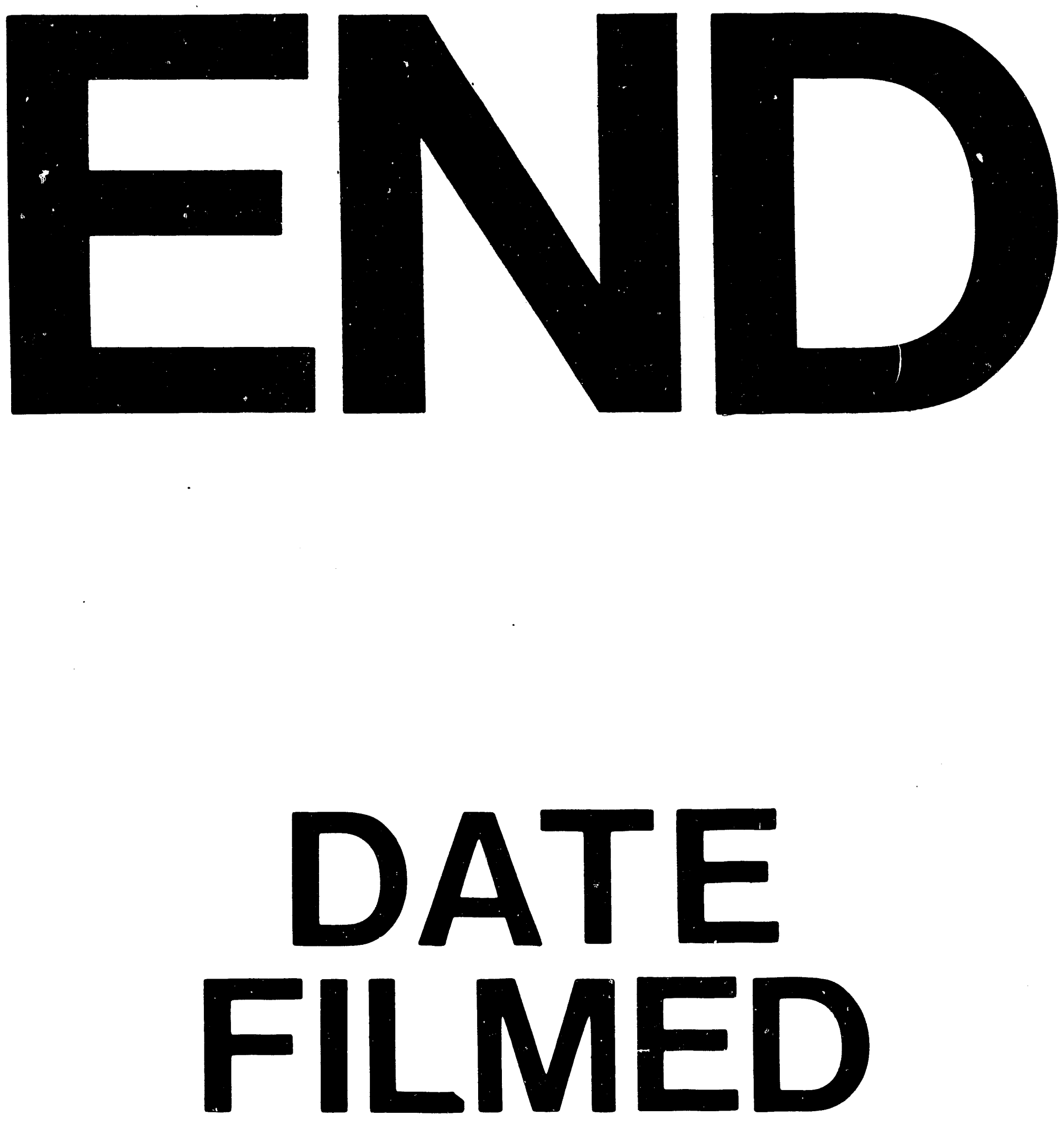

1

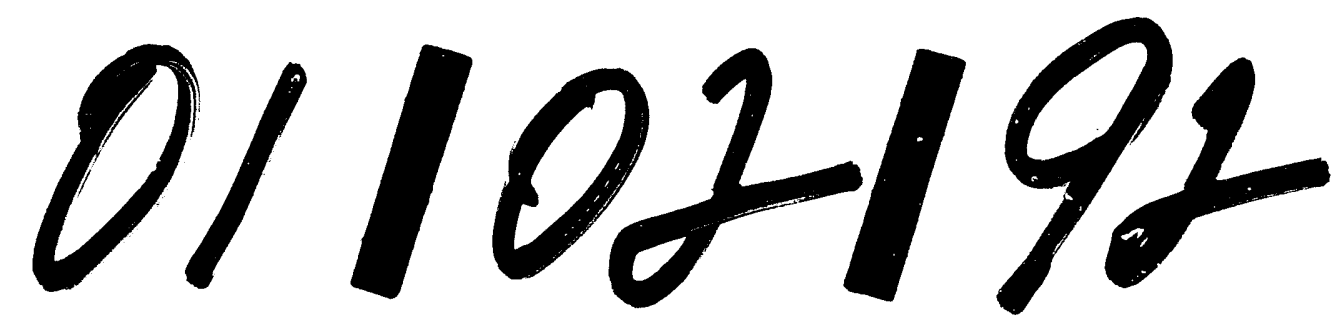


